\section{Kleines Märchen (1937)}

\subsection{Entstehung}

Seit Juli 1937 trug Döblin zur Pariser Exilzeitschrift Das neue Tage-Buch bei. Herausgeber Leopold Schwarzschild wollte sich eines Autors versichern, der "für die nichtkommunistische Linke Autorität besaß und dessen literarische Qualitäten unbestritten waren « (Schiller 1995, 46). Neben Vorabdrucken aus November 1918 veröffentlichte Döblin Essays und Kritiken (KS IV, 97, 102, 108, 114, 131und 136) sowie zwei Erzählungen; im Oktober 1937 zunächst Kleines Märchen (Das neue Tage-Buch, 5.Jg., Nr. 40, Paris, 2.10.1937, 953 f.). Ein Nachdruck mit drei Kaltnadelradierungen von Rudi Lesser erschien bei der Fuchstaler Presse in Denklingen 1984.

\subsection{Inhalt}

Das Königreich Maulfaul auf dem Erdteil `Viel Geschrei und wenig Woller schätzt das Heroische, besonders die Sprache so hoch, dass man sie möglichst wenig benutzt und sich mit Blicken und Bewegungen verständigt. Man unterrichtet praktische Dinge wie Sport. Das Denken schätzt man nicht. Die Redaktionsarbeit in den Zeitungen ist nicht beliebt, weil die Zeitung aus weißen Blättern besteht. Höhepunkt der Abwechslung ist Zeitungslektüre mit verschiedenfarbigen Brillen. Die Telefone blinken schwarz auf schwarz, und Nachrichten werden den Menschen auf Plakaten im Weiß-Satz kundgegeben. Während das Volk allmählich wieder schwatzt, behält die Regierung den Kult der >scriptura alba regia $<$, der heiligen Weißschrift, bei. Im Unterschied zu den >Parlamenten $\triangleleft$ der schwatzsüchtigen Länder heißen die Vertretungen der Maulfaulen 'Silencorien', schweigende Herzen. Dort kommuniziert man mit Verbeugungen und trinkt. So wie im Königreich Maulfaul die Sprache wird im angrenzenden Herzogtum die Freiheit behandelt. Man verwahrt sie, und einmal im Jahr gibt es Aufmärsche zu ihren Ehren. Der Fürst baut neue Gefängnisse, um alle Angreifer der Freiheit zu inhaftieren; jeder Einwohner geht turnusmäßig ins Zuchthaus. Die Freiheit lebt als alte Frau im Schloss und meint, sie sei doch nur ein Vorurteil. Die Fürstentümer Maulfaul und Freiheit tauschen regelmäßig einen Teil ihrer Bevölkerung aus und leben in guten Beziehungen.

Dieses parallel zu Der neue Urwald entstandene »Märchen der Zeitkritik» (Kümmerling-Meibauer
1991, 211) karikiert Nazideutschland und die Sowjetunion in grotesken Schablonen. Der bewusst einfache Stil spiegelt die Simplifizierungen totalitären Denkens. Als allegorisches »Modell ideologischer Unterwerfungsmechanismen" sei die Geschichte »ein wenig grob geschnitzt« (Schiller 1995, 39). Die Eliminierung der Schwarzbuchstaben kann eine Allusion auf Peter Döblin sein, der 1937 seine Arbeit als Schriftsetzer verlor. Das satirische Märchen steht in der Tradition Jonathan Swifts und Heinrich Heines und will mit der »stilistischen Verflachung « eine »breite, dem Aufnahmevermögen des Zeitungslesers entgegenkommende Wirkung der fiktionalen Aussage« erreichen (Horvat 1993, 248).

\section{Kleine Kriminalität (1937)}

Nach dem Krieg baut ein Soldat die zerschossene Mühle seines Vaters mithilfe der Mitgift seiner Frau wieder auf. Sie bekommen drei Kinder; die Liebe vergeht, die Müllerin nimmt den Knecht zum Geliebten. Der Müller schlägt den Knecht, der Geld gestohlen hat. Aus Rache führt der Knecht, der die Müllerin eigentlich verlassen wollte, deren Plan aus: Er ermordet den traumatisierten Ex-Soldaten, als dieser auf der Stube Krieg spielt. Die Tatwaffe überführt den Knecht und beide Täter werden verurteilt.

Diese zweite und letzte im Neuen Tage-Buch erschienene Erzählung (5. Jg., Nr. 45, Paris, 6.11.1937, 1078) wurde als »zeittranszendente satirische Diagnose des Spießertums « gelesen (Horvat 1993, 248). Diese Deutung lässt allerdings außer Acht, dass Kleine Kriminalität zur Zeit des »Großen Terrors" entstand, der 1936-1938 Stalins Herrschaft stabilisieren sollte. Wie im Femgericht (1917) verweist die parabolische Struktur auf (individuelle und staatliche) Schuld, indem ein geringfügiger Anlass zum Ausgangspunkt monströsen Handelns genommen wird.

\section{Literatur}

Horvat, Dragutin: Zeitmärchen als Zeitungsmärchen. In: IADK Münster/Marbach 1989/91. Bern u. a. 1993, 243 250.

Kümmerling-Meibauer, Bettina: Die Kunstmärchen von Hofmannsthal, Musil und Döblin. Köln u. a. 1991.

Schiller, Dieter: Alfred Döblins Beziehung zu den Exilzeitschriften Das neue Tage-Buch und Die Zukunft 1937 bis 1940. In: IADK Paris. Bern u. a. 1995, 37-51.

Christina Althen 